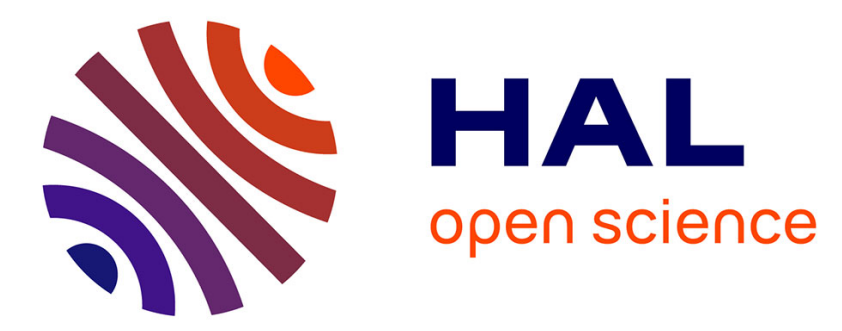

\title{
A study on the dispersion, preparation, characterization and photo-degradation of polypropylene traced with rare earth oxides
}

\author{
Feliks Bezati, Valérie Massardier, Jean Balcaen, Daniel Froelich
}

\section{- To cite this version:}

Feliks Bezati, Valérie Massardier, Jean Balcaen, Daniel Froelich. A study on the dispersion, preparation, characterization and photo-degradation of polypropylene traced with rare earth oxides. Polymer Degradation and Stability, 2010, 2011 (96), pp.51-59. 10.1016/j.polymdegradstab.2010.11.008 . hal01206733

\section{HAL Id: hal-01206733 \\ https://hal.science/hal-01206733}

Submitted on 29 Sep 2015

HAL is a multi-disciplinary open access archive for the deposit and dissemination of scientific research documents, whether they are published or not. The documents may come from teaching and research institutions in France or abroad, or from public or private research centers.
L'archive ouverte pluridisciplinaire HAL, est destinée au dépôt et à la diffusion de documents scientifiques de niveau recherche, publiés ou non, émanant des établissements d'enseignement et de recherche français ou étrangers, des laboratoires publics ou privés. 


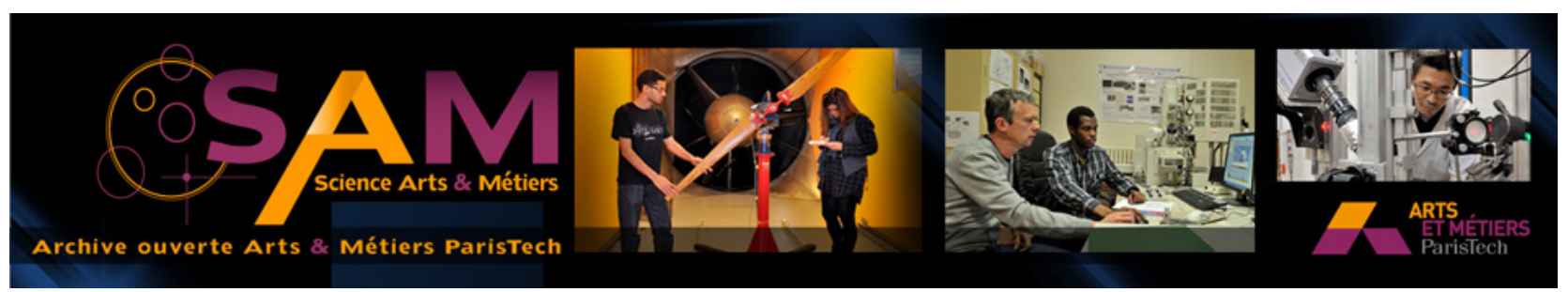

\section{Science Arts \& Métiers (SAM)}

is an open access repository that collects the work of Arts et Métiers ParisTech researchers and makes it freely available over the web where possible.

This is an author-deposited version published in: http://sam.ensam.eu

Handle ID: .http://hdl.handle.net/10985/10233

\section{To cite this version :}

Feliks BEZATI, Valérie MASSARDIER, Jean BALCAEN, Daniel FROELICH - A study on the dispersion, preparation, characterization and photo-degradation of polypropylene traced with rare earth oxides - Polymer Degradation and Stability - Vol. 2011, n96, p.51-59 - 2010 


\title{
A study on the dispersion, preparation, characterization and photo-degradation of polypropylene traced with rare earth oxides
}

\author{
Feliks Bezati $^{\mathrm{a}, \mathrm{c}, *}$, Valérie Massardier $^{\mathrm{a}}$, Jean Balcaen ${ }^{\mathrm{b}}$, Daniel Froelich ${ }^{\mathrm{c}}$ \\ a Ingénierie des Matériaux Polymères - Laboratoire des Matériaux Macromoléculaires (IMP/LMM), UMR-CNRS 5223, INSA-Lyon, 17 avenue Jean Capelle, \\ F-69621 Villeurbanne Cedex, France \\ ${ }^{\mathrm{b}}$ Site de Plasturgie-IMP/LMM, UMR-CNRS 5223, 6 rue Pierre et Marie Curie, F-01108 Oyonnax, France \\ ' Laboratoire Conception Produit Innovation, Chambéry (LCPI), Institut ARTS et METIERS ParisTech Chambéry, Savoie Technolac, 4 Rue du Lac Majeur, \\ F-73375 Le Bourget du Lac Cedex, France
}

Keywords:

Polyolefin

Rare earth oxides

Tracer

Mechanical properties

Photo-degradation

\begin{abstract}
A B S T R A C T
This research work deals with the effect of rare earth oxides on the PP matrix with respect to the thermal and mechanical properties and to the photo-degradation under UV irradiation exposure. The rare earth oxides are used as tracers for the identification of polymer materials, in order to have an economically efficient recycling and high speed automatic sorting of plastic wastes. The addition of $0.1 \mathrm{wt} \%$ of such particles of a micrometric size has a minor effect on the mechanical and thermal properties of the traced materials, as well as on the photo-degradation of the polymer after UV irradiation exposure. For $1 \mathrm{wt} \%$ tracer content, before UV irradiation treatment, the melting and crystallization temperatures as well as the thermal stability of the PP matrix are slightly increased, whereas the elongation at break decreases from 10 to $50 \%$ for a cross-head speed of $250 \mathrm{~mm} / \mathrm{min}$. However, the addition of $1 \mathrm{wt} \%$ of $\mathrm{CeO}_{2}$ improves the photo-degradation resistance of the PP matrix to UV exposure due to the UV light screening effects offered by these particles. The SEM images together with the results obtained from image processing show a homogenous dispersion of tracers in the PP matrix.
\end{abstract}

\section{Introduction}

Tracers consist of systems formed by one or several substances dispersed into a material with the aim of adding a selective property to it and improving its identification. In recent works [1,2], an X-ray fluorescence (XRF) detection system based on the use of tracers for the identification of polymer materials was reported by the authors. This system was developed with the objective of having an economical, efficient and automatic sorting of plastic wastes. The addition of X-ray fluorescent tracers in polymer materials during the compounding process, offers many benefits by increasing the efficiency and purity of sorting and providing a solution for the identification of dark plastics.

Tracers must not chemically react with the host material, and cause changes to any of their physical, chemical or mechanical properties beyond acceptable limits. For products which are likely to have long useful lives under normal outdoor environment, such

\footnotetext{
* Corresponding author. Ingénierie des Matériaux Polymères - Laboratoire des Matériaux Macromoléculaires (IMP/LMM) UMR-CNRS 5223, INSA-Lyon 17 avenue Jean Capelle, F-69621 Villeurbanne Cedex, France. Tel.: +33 (0) 472436 003; fax: + 33 (0) 472438527.

E-mail address: feliks.bezati@insa-lyon.fr (F. Bezati).
}

as automotive parts, the tracer particles need to be highly stable under weathering and during plastic processing [3].

The automotive and electrical industries are currently the worst performers concerning the recycling of plastics. This is partly due to the complexity of the waste materials that these sectors produce [4]. For this study, polypropylene (PP), one of the world's major plastics, abundantly present in polymers to be recycled from the End of Life Vehicles (ELV) and the Waste of Electric and Electronic Equipments (WEEE) was chosen.

$\mathrm{XRF}$ is a volume, non-destructive spectroscopic method enabling elemental analysis of materials. Therefore the choice of tracers is directly linked to the elements of the periodic table. Once the toxic and radioactive elements are eliminated, along with the elements present in polymer additives, the low atomic number elements and the elements with limited reserves, the result leads to the selection of rare earth elements. For these selected ones we have chosen the most stable chemical molecules, the oxides [5]. The rare earth oxides $\left(\mathrm{Y}_{2} \mathrm{O}_{3}, \mathrm{CeO}_{2}, \mathrm{Nd}_{2} \mathrm{O}_{3}, \mathrm{Gd}_{2} \mathrm{O}_{3}, \mathrm{Dy}_{2} \mathrm{O}_{3}, \mathrm{Er}_{2} \mathrm{O}_{3}\right.$ and $\left.\mathrm{Yb}_{2} \mathrm{O}_{3}\right)$ used for this study are neither abrasive, nor toxic during their application and use and also stable in the environment [6,7].

The minerals used as fillers in polypropylene are principally talc and calcium carbonate. However, little attention has been paid to 
Table 1

Materials specifications.

\begin{tabular}{lllc}
\hline Materials & Chemical name & Supplier & $\begin{array}{c}\text { Particles' size } \\
(\mu \mathrm{m})\end{array}$ \\
\hline $\mathrm{PP}$ & Polypropylene & REPSOL & 2000 \\
$\mathrm{Y}_{2} \mathrm{O}_{3}$ & Yttrium oxide & RHODIA & 2.250 \\
$\mathrm{CeO}_{2}$ & Cerium oxide & RHODIA & 2.250 \\
$\mathrm{Nd}_{2} \mathrm{O}_{3}$ & Neodymium oxide & AMPERE & 3.500 \\
$\mathrm{Gd}_{2} \mathrm{O}_{3}$ & Gadolinium oxide & RHODIA & 1.850 \\
$\mathrm{Dy}_{2} \mathrm{O}_{3}$ & Dysprosium oxide & RHODIA & 2.250 \\
$\mathrm{Er}_{2} \mathrm{O}_{3}$ & Erbium oxide & AMPERE & 8.200 \\
$\mathrm{Yb}_{2} \mathrm{O}_{3}$ & Ytterbium oxide & AMPERE & 1.000 \\
\hline
\end{tabular}

rare earth compounds used as fillers in polymers. As rare earth minerals are abundant in China, some studies investigating polypropylene composites containing rare earth oxides were published by Chinese scientific committees. Liu et al. $[8,9]$ have studied the effect of a large number of rare earth oxides on isothermal crystallization and melting behaviour with differential scanning calorimetry. They found that a series of rare earth oxides in a fine powder form may act as a nucleating agent and influence the growth rate of the spherulite and the mechanical properties of polypropylene. Other studies of Xiaomin et al. [10] have shown that the addition of $\mathrm{Y}_{2} \mathrm{O}_{3}$ has some effect on the viscosity of the system. Crystallization characteristics have indicated that the filler acts as a nucleating agent, increasing crystallization rate of the investigated polymer, and changing $\beta$ crystal form content.

Regarding the effect of rare earth oxides in photo-degradation, cerium oxide $\left(\mathrm{CeO}_{2}\right)$ nanoparticles are used in wood coating technologies as UV absorbers [11], as they show a UV cut-off threshold at around $370 \mathrm{~nm}$, similar to that of titanium oxide. The use of fine particles of cerium oxide has also been mentioned as an effective inorganic sunscreen for personal care products for replacing titanium and zinc oxides [12]. Tessier et al. [13] have studied $\mathrm{Y} / \mathrm{Ce}$ substitution of ceria in order to shift efficiently the absorption edge towards the UV/Vis transition $(400 \mathrm{~nm})$. They have concluded that the compositions proposed are interesting for UV absorbers applications for the wood industry. Moreover, the use of Yttrium oxide $\left(\mathrm{Y}_{2} \mathrm{O}_{3}\right)$ was mentioned in literature for its application as a protector of aluminium and silver mirror coatings, due to its capacity to absorb widely in the near-UV spectrum $(300 \mathrm{~nm})[14,15]$.

Following the above mentioned previous works [1,2], which report the possibility of detecting rare earth oxides through the use of XRF, our study presents a complementary approach with a research on the dispersion, elaboration, characterization and photo-degradation of traced polypropylene with rare earth oxides. The main objectives of this study are first, to quantitatively characterize the dispersion of tracers in the PP matrix which is of prime importance for their detection and for the mechanical properties of the traced PP. Second, to study the effect of tracers as fillers in the PP matrix with respect to the thermal and mechanical properties and to the photo-degradation under UV irradiation exposure. Third, to finally estimate the tracer concentration for which the properties of the polymer matrix will not be affected.

\section{Experimental}

\subsection{Materials and preparation of traced polypropylene composites}

The investigation described in this paper was conducted with a commercial grade of isotactic polypropylene homopolymer (ISPLEN PP 050 G1E) manufactured by Repsol. The original pellets have a melt mass-flow rate of $5.8 \mathrm{~g} / 10 \mathrm{~min}\left(2.16 \mathrm{~kg}\right.$ at $\left.230^{\circ} \mathrm{C}\right)$ and a density of $0.905 \mathrm{~g} / \mathrm{cm}^{3}$. ISPLEN PP $050 \mathrm{G} 1 \mathrm{E}$ is intended for applications that require good impact resistance and is believed to contain low quantities of UV stabilizers and a small amount of heat stabilizer in order to minimize degradation during processing.

The characteristics of the rare earth oxides used as tracers are given in Table 1 . The tracer content in the composites is 0.1 and $1 \%$, respectively. All traced materials were prepared under identical mixing and moulding conditions. The injection moulded specimens of $2 \mathrm{~mm}$ thickness were produced by using a Battenfeld Unilog B2/350 Plus injection moulding machine. The barrel temperature was fixed at $220{ }^{\circ} \mathrm{C}$ for all zones. Before being injected the pellets were extruded twice by using a twin screw extruder CLEXTRAL BC21 machine (screw of $\mathrm{L} / \mathrm{D}=90$ and $\mathrm{D}=25 \mathrm{~mm}$ ) for dispersing homogenously the tracers in the PP matrix. The extrusion temperature, the screw speed and the residence time were $205{ }^{\circ} \mathrm{C}, 120 \mathrm{rpm}$ and $15 \mathrm{~min}$, respectively. The screw and temperature profiles used in this study are supplied in Fig. 1.

For PP containing 0, 0.1 and $1 \mathrm{wt} \%$ of tracers (T), the materials will be designed as PP, PP_T_0.1 and PP_T_1, respectively. For the samples subjected to UV irradiation treatment, they will be referred to as UV-PP, UV-PP_T_0.1 and UV-PP_T_1, respectively.

All samples were kept for at least 1 month at room temperature before undergoing UV exposure in order to ensure that they had reached a near-equilibrium state, following ageing due to postmoulding effects such as secondary crystallization.

\subsection{Microscopic observation}

The tracers and their dispersion in the PP matrix were observed by Scanning Electron Microscopy (SEM) using a Hitachi S3500N model. The specimens prepared by injection moulding were fractured in liquid nitrogen and sputter-coated with gold before being examined with the microscope at an accelerating voltage of $30 \mathrm{kV}$. The SEM images were analysed by MATLAB by applying image processing.

\subsection{UV irradiation procedure}

UV irradiation treatment for the injection moulded specimens were carried out using a QUV accelerated weathering machine (QUV Solar Eye), with a light intensity of $0.68 \mathrm{~W} / \mathrm{m}^{2}$. The source of UV radiation was fluorescent tubes UVA-340, which have an output matching reasonably close to the solar radiation in the UV range [16]. The surface of the samples was subjected to a cycle of $4 \mathrm{~h}$ of UV irradiation at $60{ }^{\circ} \mathrm{C}$ and $4 \mathrm{~h}$ of condensation at $50{ }^{\circ} \mathrm{C}$. The total exposure time of specimens was $2160 \mathrm{~h}$ ( 3 months).

\begin{tabular}{|c|c|c|c|c|c|c|c|c|}
\hline $\begin{array}{l}\text { Zone } 1 \\
80^{\circ} \mathrm{C}\end{array}$ & $\begin{array}{l}\text { Zone } 2 \\
160^{\circ} \mathrm{C}\end{array}$ & $\begin{array}{l}\text { Zone } 3 \\
205^{\circ} \mathrm{C}\end{array}$ & $\begin{array}{l}\text { Zone } 4 \\
205^{\circ} \mathrm{C}\end{array}$ & $\begin{array}{l}\text { Zone } 5 \\
205^{\circ} \mathrm{C}\end{array}$ & $\begin{array}{l}\text { Zone } 6 \\
205^{\circ} \mathrm{C}\end{array}$ & $\begin{array}{l}\text { Zone } 7 \\
205{ }^{\circ} \mathrm{C}\end{array}$ & $\begin{array}{l}\text { Zone } 8 \\
205^{\circ} \mathrm{C}\end{array}$ & $\begin{array}{l}\text { Zone } 9 \\
205^{\circ} \mathrm{C}\end{array}$ \\
\hline
\end{tabular}

Fig. 1. Screw and temperature profiles for the extrusion processing. 

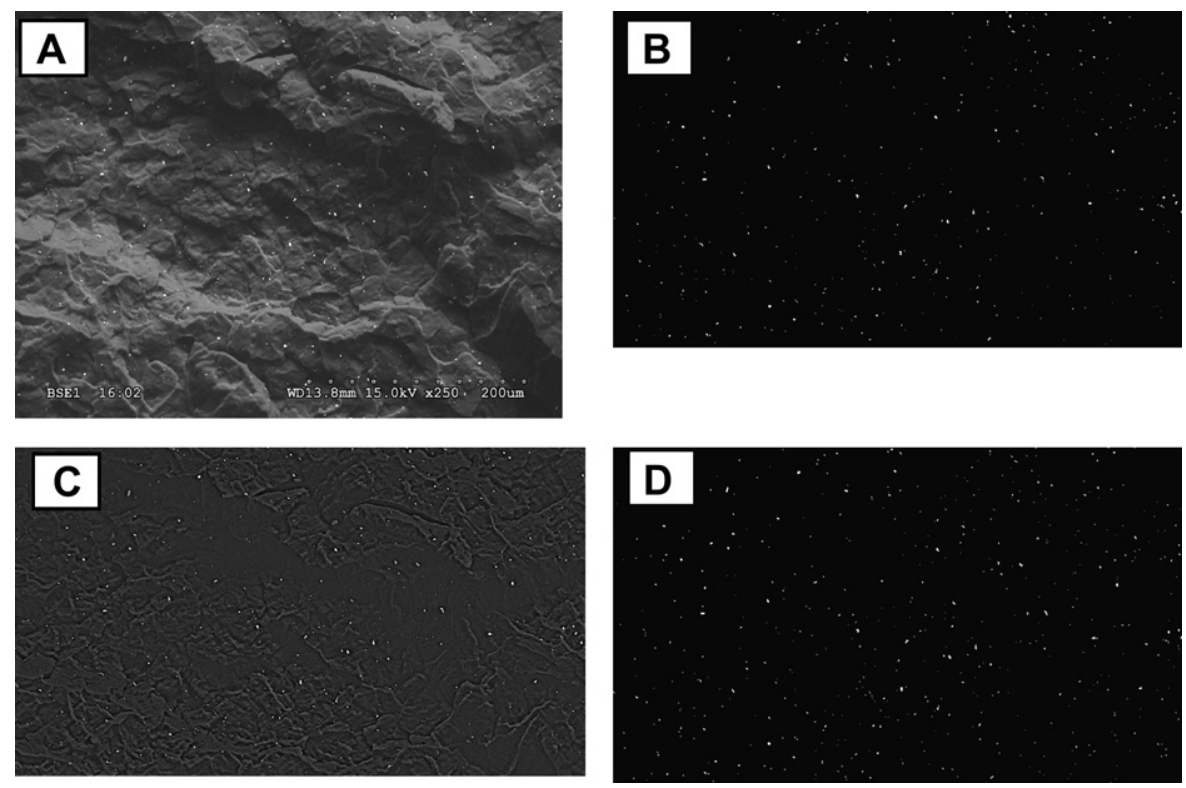

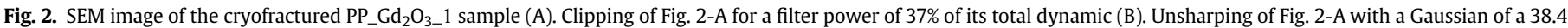
pixels equivalent $\sigma(\mathrm{C})$. Clipping of Fig. $2-\mathrm{C}$ for a filter power of $20 \%$ of its total dynamic (D).

\subsection{Infrared spectroscopy}

Samples used for Fourier transform infrared spectroscopy (FTIR), were collected from the surface to a depth of $0.5 \mathrm{~mm}$ and powdered. Approximately, $1-2 \mathrm{mg}$ of the material powder was mixed and cold pressed with $\mathrm{KBr}$ to produce discs. FTIR measurements were obtained in transmission through the discs with a Nicolet Magna-IR 550 spectrometer. The equipment operates with a resolution of $2 \mathrm{~cm}^{-1}$ at a transmission mode using 16 scans.

\subsection{Differential scanning calorimetry (DSC) characterization}

Differential scanning calorimetry characterization (DSC Q10, TA Instruments) was performed to investigate the crystallization and the melting behaviours of the traced material. Thin slices of samples about $0.5 \mathrm{~mm}$ thick and 5-10 $\mathrm{mg}$ weight were cut from the surfaces of the specimens for the measurement. Thermograms were recorded in three consecutive runs: (1) a first heating, from room temperature to $210{ }^{\circ} \mathrm{C}$, followed by (2) cooling, from 210 to $25{ }^{\circ} \mathrm{C}$ after holding the sample at $210{ }^{\circ} \mathrm{C}$ for $5 \mathrm{~min}$, and finally (3) a second heating, from 25 to $210{ }^{\circ} \mathrm{C}$. All experiments were performed at heating/cooling rate of $10{ }^{\circ} \mathrm{C} / \mathrm{min}$ under argon atmosphere to avoid thermal degradation. The degree of crystallization, $\chi_{c}$, was calculated considering a melting enthalpy of $209 \mathrm{~J} / \mathrm{g}$ for a $100 \%$ crystalline polypropylene [17].

\subsection{Thermal stability analysis}

A TA Instruments Q500 Thermogravimetric Analyzer was used to characterize the thermal stability of specimens before and after UV irradiation. Measurements were conducted under an argon flow rate of $90 \mathrm{~mL} / \mathrm{min}$ at a heating rate of $20^{\circ} \mathrm{C} / \mathrm{min}$. The scanning temperature ranged from 25 to $500{ }^{\circ} \mathrm{C}$. Similar to the DSC characterizations, thin slices of samples about $0.5 \mathrm{~mm}$ thick and $10-15 \mathrm{mg}$ weight were cut from specimens for the measurement. The temperature at $5 \%$ weight loss $\left(T_{-5} \%\right.$ ) and the temperature of maximum decomposition rate $\left(T_{\max }\right)$ were calculated for each traced PP sample.

\subsection{Mechanical characterization}

Mechanical testing was carried out on specimens, prepared according to ISO 527-1:1993, using an Instron 4469 uniaxial tensile testing machine. Yield stress and elongation at break were measured at ambient temperature for a cross-head speed of $250 \mathrm{~mm} / \mathrm{min}$ and the values reported represent an average of six measurements.

\section{Results and discussions}

\subsection{Characterization of the dispersion of tracers}

The homogenous dispersion of the filler particles in the PP matrix is of prime importance since it may strongly affect their detection and the mechanical properties [18,19]. Therefore, a quantitative characterization of the dispersion status of the

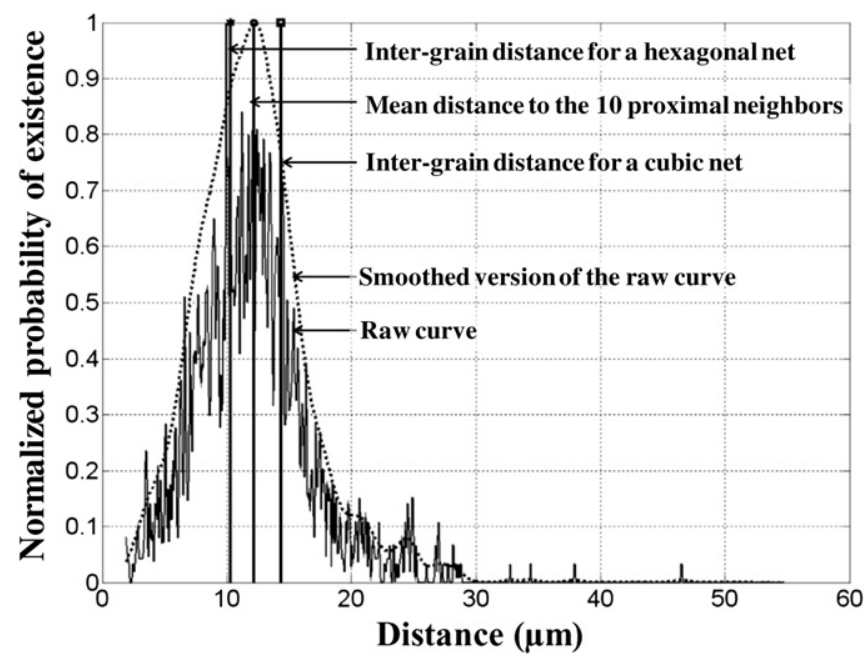

Fig. 3. Curve of spatial dispersion of charges, normalised to the most probable interparticle distance for the PP_Gd ${ }_{2} \mathrm{O}_{3} \_1$ sample. 


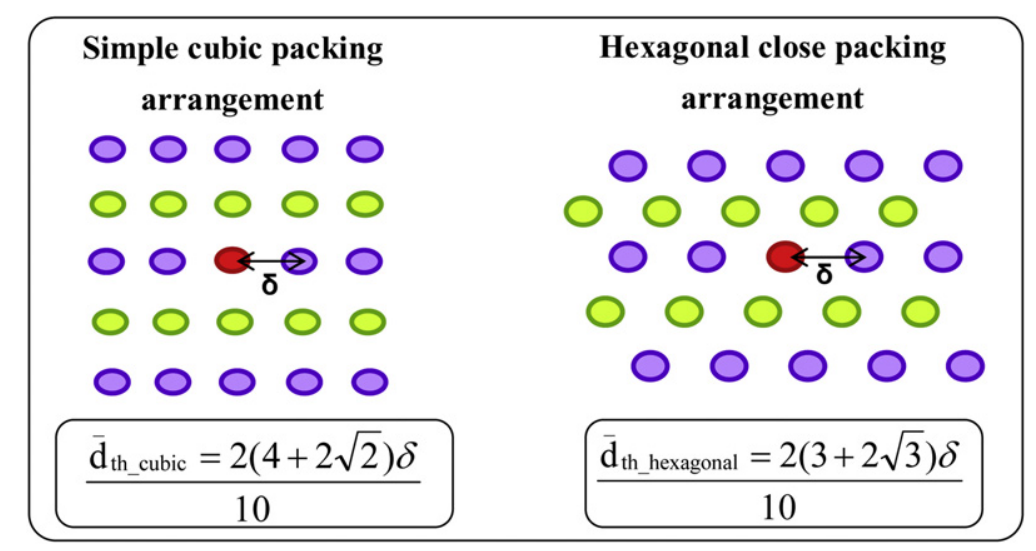

Fig. 4. Cubic and hexagonal close packing arrangement representation.

tracers is important for understanding their distribution in the PP matrix. Image analysis may be a powerful tool for describing quantitatively the dispersion of tracers, but this technique is subtle and delicate to use. The quality of results is highly dependent on the user's knowledge of this technique. In particular, the setting parameters are able to create artefacts or erase a part of the information and by this way bias the results. Consequently, the processed images should show a high contrast between the objects (rare earth oxides) and their environment (PP matrix). The image processing must be subject to an easy programmable criterion uniformly applicable to all images in question.

In our case, the objective is to extract the rare earth oxides particles from a polymer matrix by SEM. The use of back scattered electrons simplifies the identification of tracers since the atomic number of rare earth oxides is higher than the elements composing the polymer matrix. This difference in the atomic weight contrast makes them appear like white dots on a black background.

In order to have a global view of the distribution of tracers, the samples have to be fractured so as to visualize the particles in material's depth. This consideration causes two main problems. First, the slice of polymer material at ambient temperature makes them melt in front of the blade and second, as rare earth oxides are rigid particles, they break in multiple parts under blade pressure by modifying their geometrical properties.

To avoid these problems so as to conserve charge and matrix geometry, the cryofracture method was chosen for sample preparation. However, this method creates a relief in the SEM images which may interfere with the detection of rare earth oxides. Likewise, as non-specific interactions between charge and matrix are known, the fracture will propagate preferentially from charge to charge by probably inducing an over evaluation of charge population.

The SEM image of PP matrix containing $1 \%$ of gadolinium oxide is given in Fig. 2-A. Even if the image shows a good contrast between charge and matrix, the relief creates illumination variation which makes the charge extraction from the matrix complicated.

For this reason, it is necessary to obtain an image in which each pixel attributed to a charge will get the value " 1 " and each pixel attributed to the matrix will get the value " 0 ". One way to obtain this binarisation is by clipping. Threshold value is made by minimising environmental residue while maximising charge visibility. The choice of this value is a very important parameter and is taken by comparing the original SEM image to the proceeded one.

Fig. 2-B shows the thresholding image for a filter of $37 \%$ of its total dynamic. In the dark part of the image it can be observed a loss of "white dots", compared to the original SEM image, which may bias the distribution results.

One of the charge properties not used in the previous thresholding process is their small size compared to the relief. This property can be used by applying a classic image processing named "unsharping", consisting in blurring a copy of the image, mostly with a convolution by a Gaussian function, and subtract it from the original image with the aim of only saving the fine details. As it can be seen in Fig. 2-C, the relief is mitigated while the charge remains as white as before the processing.

After the "unsharping" process the image of Fig. 2-C was also proceeded to a clipping and the obtained image is shown in Fig. 2D. A point to point comparison between the original image and the processed one shows that quality has been improved. Thus the charge surface on the image passed from $0.26 \%$ for the simple
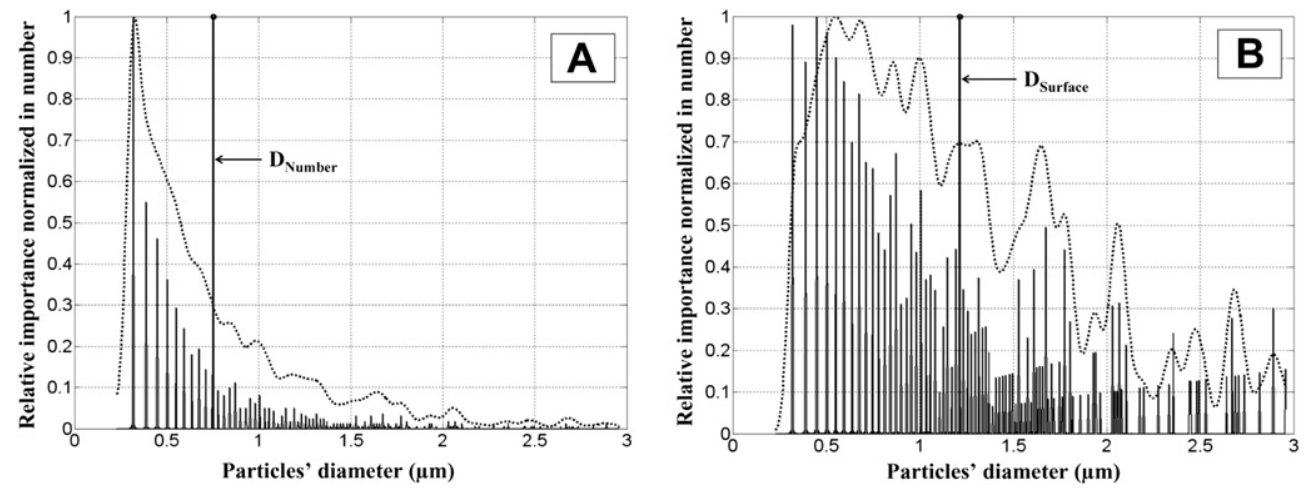

Fig. 5. Number average distribution of particles' diameter for the $\mathrm{PP}_{-} \mathrm{Gd}_{2} \mathrm{O}_{3}{ }_{-} 1$ sample (A) Surface average distribution of particles' diameter for the PP_Gd $\mathrm{O}_{3}{ }_{-} 1$ sample (B). 


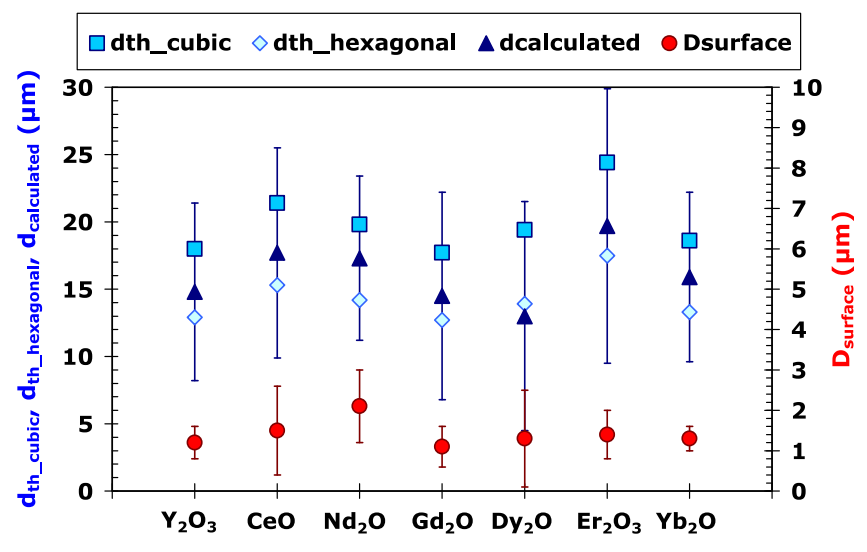

Fig. 6. Image processing results obtained by MATLAB

clipping to $0.38 \%$ for the unsharped thresholding by increasing to $36 \%$ the charge gain.

Once the image has been binarised, the coordinates of the constitutive points of the charge can be extracted. From this data, multiple parameters like gravity centre position of each particle and their size can be obtained. The gravity centre position can be used for characterizing the dispersion of the charge in the matrix. The mean distance from a particle to all the others can be affected by boundary effects and the minimal distance to the first neighbours is extremely sensitive to object fragmentation. In order to minimize boundary and local effects the mean distance to the first ten neighbouring particles was chosen as a representative value.

Fig. 3 presents the curve of spatial dispersion of the first ten neighbouring particles distances for the PP_ $\mathrm{Gd}_{2} \mathrm{O}_{3}{ }_{1} 1$ sample. The noisy spectrum (raw curve) corresponds to the number of counted particles. This number is a consequence of the sampling and the scale chosen for the image. The image sampling should be chosen between $1 / 10$ and $1 / 100$ of the inter-particle distance in order to have a reasonable sampling noise on each measure. Thus, as the image has a characteristic scale of $1000 \times 1000$ pixel, the number of particles will be about $100-1000$ by image (in our case, 1421 objects in a $2560 \times 1920$ pixels image), and as they are represented on a scale of 1000 step, most of them are visible individually.

For comparing the results given by image processing, Fig. 3 shows the mean distance to the ten proximal neighbouring particles in a cubic and hexagonal close packing arrangement of the same surface and the same number of particles as in the case of the experimental data. As it can be seen in Fig. 4 the hexagonal network

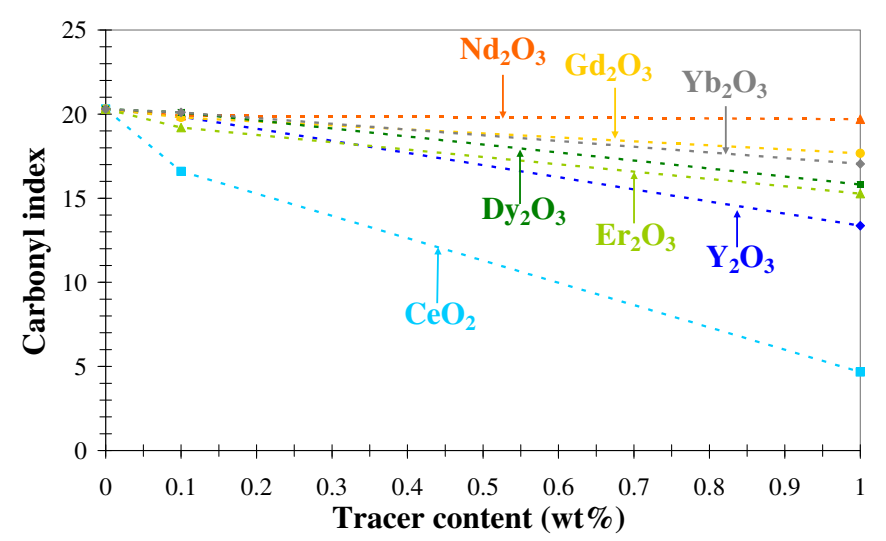

Fig. 8. Effect of tracers and their content on the carbonyl index.

is more isotropic at low scale than the cubic one and this is the reason why the mean distance appears shorter.

Fig. 5-A, B gives the results of the particles diameter dispersion in number and in surface, respectively. As it can be seen, the distribution of the particles diameter in number follows a decreasing exponential curve, which can be explained by the fact that during the extrusion process particles are subject to brittle in smallest pieces. However, the distribution of particles diameter in surface is represented by a linearly decreasing curve showing the importance of each population.

The results obtained for the distance of the first ten neighbouring spheres $\left(\mathrm{d}_{\text {calculated }}\right)$ calculated for the SEM data and the theoretical distance for a cubic $\left(\mathrm{d}_{\text {th_cubic }}\right)$ and hexagonal $\left(\mathrm{d}_{\mathrm{th} \_ \text {hex }}\right.$ agonal) close packing arrangement, together with average diameter in number $\left(D_{\text {Number }}\right)$ and average diameter in surface $\left(D_{\text {Surface }}\right)$ are given in Fig. 6.

For characterizing the rare earth oxides dispersion in the PP matrix, the mean distance of the first ten neighbouring spheres calculated for the SEM data $\left(\mathrm{d}_{\text {calculated }}\right)$ was compared with the theoretical distance for a cubic $\left(\mathrm{d}_{\mathrm{th} \_ \text {cubic }}\right)$ or hexagonal $\left(\mathrm{d}_{\mathrm{th} \_ \text {hexagonal }}\right)$ close packing arrangement. As $\mathrm{d}_{\text {calculated }}$ is ranged between the cubic and hexagonal theoretical values this implies that the dispersion isotropy is quite good and homogenous. Moreover the SEM image of Fig. 2-A leads to the same conclusion.

\subsection{Stability under UV irradiation/condensation cycles}

The main products of polypropylene degradation, carbonyls, are easily observed in the wavelength range $\left[1700-1800 \mathrm{~cm}^{-1}\right]$ by
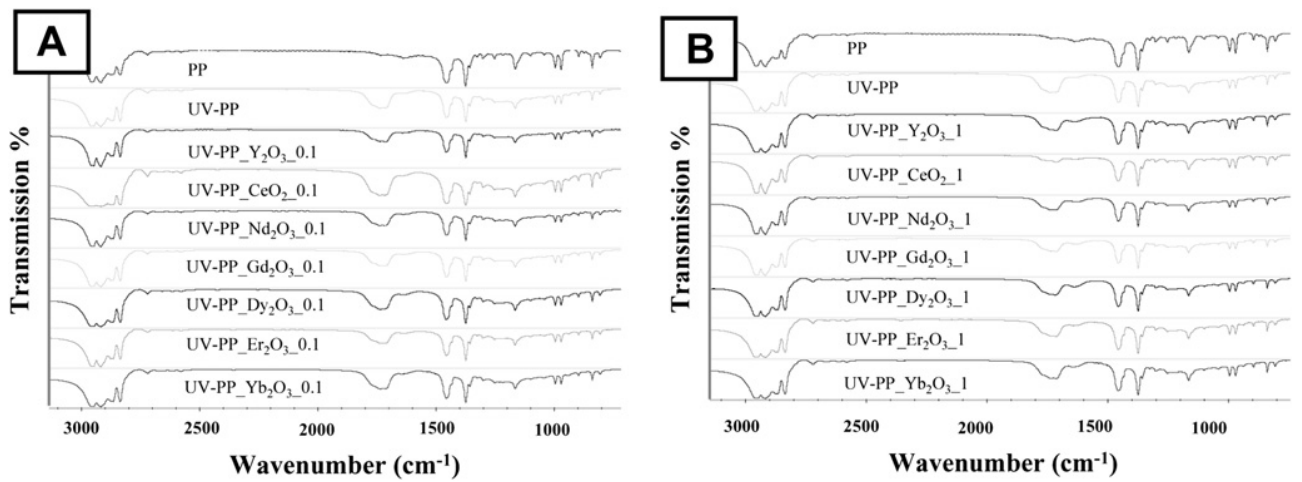

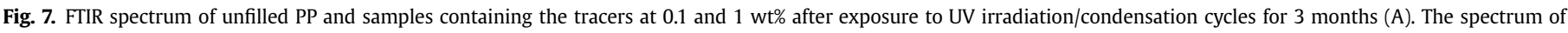
unexposed unfilled PP is also shown (B). 
Table 2

Thermal and crystallization data obtained from DSC before UV irradiation exposure.

\begin{tabular}{|c|c|c|c|c|c|}
\hline Sample & $\Delta \mathrm{H}_{\mathrm{f}}\left(\mathrm{J} / \mathrm{g}_{\mathrm{PP}}\right)$ & $\mathrm{T}_{\mathrm{m}}\left({ }^{\circ} \mathrm{C}\right)$ & $\Delta \mathrm{H}_{\mathrm{c}}\left(\mathrm{J} / \mathrm{g}_{\mathrm{PP}}\right)$ & $\mathrm{T}_{\mathrm{c}}\left({ }^{\circ} \mathrm{C}\right)$ & $\chi_{c}(\%)$ \\
\hline PP & $110 \pm 3$ & $167.0 \pm 0.5$ & $100 \pm 3$ & $105.0 \pm 0.5$ & $53 \pm 1$ \\
\hline PP_Y ${ }_{2} \mathrm{O}_{3} \_0.1$ & $113 \pm 3$ & $166.5 \pm 0.5$ & $103 \pm 3$ & $106.9 \pm 0.5$ & $54 \pm 1$ \\
\hline PP_CeO $2 \_0.1$ & $110 \pm 3$ & $166.1 \pm 0.5$ & $100 \pm 3$ & $108.1 \pm 0.5$ & $52 \pm 1$ \\
\hline PP_Nd ${ }_{2} \mathrm{O}_{3} \_0.1$ & $108 \pm 3$ & $167.1 \pm 0.5$ & $99 \pm 3$ & $106.3 \pm 0.5$ & $52 \pm 1$ \\
\hline PP_Gd ${ }_{2} \mathrm{O}_{3} \_0.1$ & $109 \pm 3$ & $166.1 \pm 0.5$ & $99 \pm 3$ & $108.4 \pm 0.5$ & $52 \pm 1$ \\
\hline PP_Dy ${ }_{2} \mathrm{O}_{3} \_0.1$ & $109 \pm 3$ & $167 \pm 0.5$ & $99 \pm 3$ & $105.1 \pm 0.5$ & $52 \pm 1$ \\
\hline $\mathrm{PP} \_\mathrm{Er}_{2} \mathrm{O}_{3} \_0.1$ & $107 \pm 3$ & $166.6 \pm 0.5$ & $96 \pm 3$ & $105.5 \pm 0.5$ & $51 \pm 1$ \\
\hline PP_Yb ${ }_{2} \mathrm{O}_{3} \_0.1$ & $111 \pm 3$ & $166.8 \pm 0.5$ & $101 \pm 3$ & $105.9 \pm 0.5$ & $53 \pm 1$ \\
\hline $\mathrm{PP}_{-} \mathrm{Y}_{2} \mathrm{O}_{3} \_1$ & $112 \pm 3$ & $166.6 \pm 0.5$ & $103 \pm 3$ & $105.9 \pm 0.5$ & $53 \pm 1$ \\
\hline PP_CeO $2 \_1$ & $107 \pm 3$ & $166.3 \pm 0.5$ & $99 \pm 3$ & $107.4 \pm 0.5$ & $51 \pm 1$ \\
\hline PP_Nd ${ }_{2} \mathrm{O}_{3} \_1$ & $111 \pm 3$ & $166.0 \pm 0.5$ & $99 \pm 3$ & $106.3 \pm 0.5$ & $53 \pm 1$ \\
\hline PP_Gd ${ }_{2} \mathrm{O}_{3} \_1$ & $110 \pm 3$ & $167.2 \pm 0.5$ & $102 \pm 3$ & $108.3 \pm 0.5$ & $53 \pm 1$ \\
\hline PP_Dy ${ }_{2} \mathrm{O}_{3} \_1$ & $107 \pm 3$ & $167.1 \pm 0.5$ & $98 \pm 3$ & $107.6 \pm 0.5$ & $51 \pm 1$ \\
\hline PP_Er ${ }_{2} \mathrm{O}_{3-1}$ & $107 \pm 3$ & $166.4 \pm 0.5$ & $98 \pm 3$ & $105.9 \pm 0.5$ & $51 \pm 1$ \\
\hline $\mathrm{PP}_{-} \mathrm{Yb}_{2} \mathrm{O}_{3-1} 1$ & $108 \pm 3$ & $166.8 \pm 0.5$ & $99 \pm 3$ & $106.1 \pm 0.5$ & $51 \pm 1$ \\
\hline
\end{tabular}

Table 3

Thermal and crystallization data obtained from DSC after UV irradiation exposure.

\begin{tabular}{|c|c|c|c|c|c|}
\hline Sample & $\Delta \mathrm{H}_{\mathrm{f}}\left(\mathrm{J} / \mathrm{g}_{\mathrm{PP}}\right)$ & $\mathrm{T}_{\mathrm{m}}\left({ }^{\circ} \mathrm{C}\right)$ & $\Delta \mathrm{H}_{\mathrm{c}}\left(\mathrm{J} / \mathrm{g}_{\mathrm{PP}}\right)$ & $\mathrm{T}_{\mathrm{c}}\left({ }^{\circ} \mathrm{C}\right)$ & $\chi_{c}(\%)$ \\
\hline UV-PP & $97 \pm 3$ & $137.6 \pm 0.5$ & $89 \pm 3$ & $100.3 \pm 0.5$ & $47 \pm 1$ \\
\hline UV-PP_Y ${ }_{2} \mathrm{O}_{3} \_0.1$ & $98 \pm 3$ & $139.8 \pm 0.5$ & $86 \pm 3$ & $100.8 \pm 0.5$ & $47 \pm 1$ \\
\hline UV-PP_CeO 2_0.1 & $93 \pm 3$ & $144.8 \pm 0.5$ & $98 \pm 3$ & $106.8 \pm 0.5$ & $45 \pm 1$ \\
\hline UV-PP_Nd ${ }_{2} \mathrm{O}_{3}-0.1$ & $100 \pm 3$ & $139.1 \pm 0.5$ & $89 \pm 3$ & $100.0 \pm 0.5$ & $48 \pm 1$ \\
\hline UV-PP_Gd ${ }_{2} \mathrm{O}_{3}-0.1$ & $107 \pm 3$ & $138.4 \pm 0.5$ & $94 \pm 3$ & $101.7 \pm 0.5$ & $51 \pm 1$ \\
\hline UV-PP_Dy $2 \mathrm{O}_{3} \_0.1$ & $102 \pm 3$ & $135.8 \pm 0.5$ & $92 \pm 3$ & $100.4 \pm 0.5$ & $49 \pm 1$ \\
\hline UV-PP_Er ${ }_{2} \mathrm{O}_{3}-0.1$ & $108 \pm 3$ & $139.6 \pm 0.5$ & $93 \pm 3$ & $100.6 \pm 0.5$ & $51 \pm 1$ \\
\hline UV-PP_Yb ${ }_{2} \mathrm{O}_{3} \_0.1$ & $92 \pm 3$ & $138.4 \pm 0.5$ & $92 \pm 3$ & $102.1 \pm 0.5$ & $44 \pm 1$ \\
\hline UV-PP_Y ${ }_{2} \mathrm{O}_{3-1}$ & $96 \pm 3$ & $138.2 \pm 0.5$ & $97 \pm 3$ & $101.6 \pm 0.5$ & $46 \pm 1$ \\
\hline UV-PP_CeO 2 _1 & $93 \pm 3$ & $164.8 \pm 0.5$ & $99 \pm 3$ & $107.2 \pm 0.5$ & $44 \pm 1$ \\
\hline UV-PP_Nd ${ }_{2} \mathrm{O}_{3} \_1$ & $95 \pm 3$ & $141.1 \pm 0.5$ & $89 \pm 3$ & $101.7 \pm 0.5$ & $46 \pm 1$ \\
\hline UV-PP_Gd ${ }_{2} \mathrm{O}_{3} \_1$ & $99 \pm 3$ & $138.2 \pm 0.5$ & $87 \pm 3$ & $101.2 \pm 0.5$ & $48 \pm 1$ \\
\hline UV-PP_Dy $2 \mathrm{O}_{3}{ }_{1} 1$ & $95 \pm 3$ & $145.6 \pm 0.5$ & $91 \pm 3$ & $102.6 \pm 0.5$ & $46 \pm 1$ \\
\hline UV-PP_Er ${ }_{2} \mathrm{O}_{3} \_1$ & $95 \pm 3$ & $140.6 \pm 0.5$ & $93 \pm 3$ & $101.3 \pm 0.5$ & $46 \pm 1$ \\
\hline UV-PP_Yb ${ }_{2} \mathrm{O}_{3}{ }_{1} 1$ & $104 \pm 3$ & $141.5 \pm 0.5$ & $91 \pm 3$ & $100.3 \pm 0.5$ & $50 \pm 1$ \\
\hline
\end{tabular}

giving a fairly broad peak as shown in Fig. 7 [20]. In addition, for a more quantitative characterization of the PP molecular degradation, the carbonyl index, corresponding to the areas under the carbonyl peak divided by the area of a reference peak was calculated, Fig. 8. For the reference, several peaks were found in

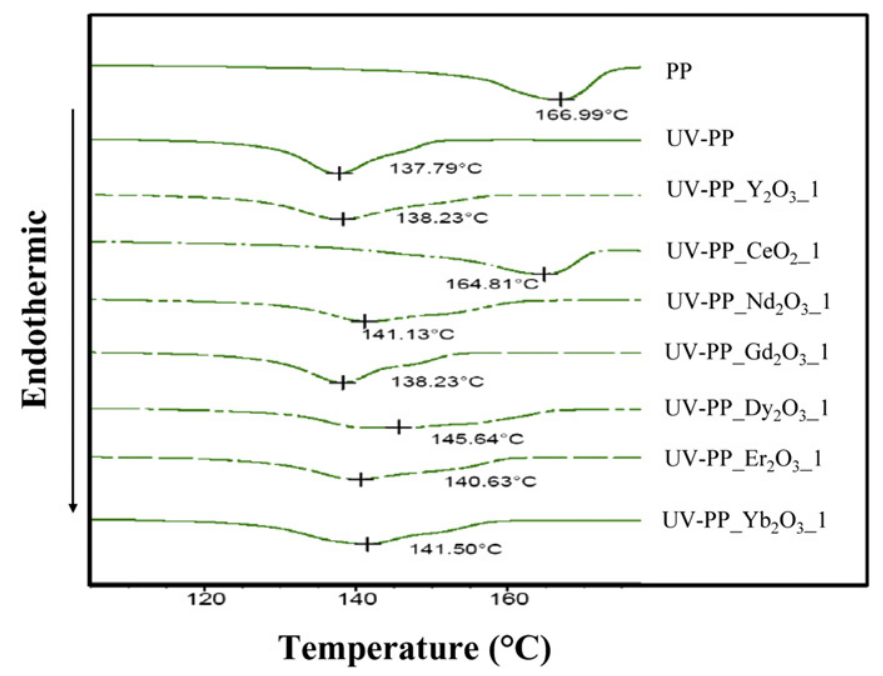

Fig. 9. Second heating run DSC thermograms of the PP samples of $1 \mathrm{wt} \%$ tracer content exposed to UV irradiation compared to the unexposed unfilled PP.
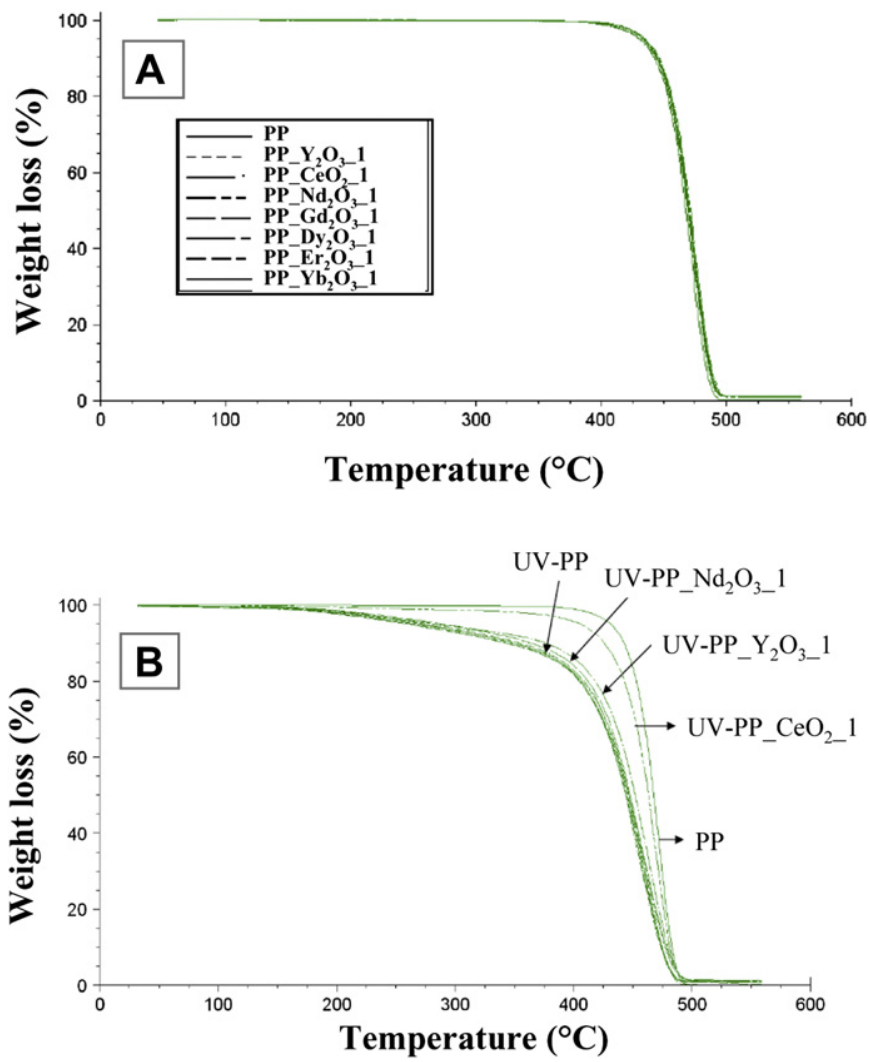

Fig. 10. TGA curves of the PP samples of 1 wt\% tracer, before (A) and after (B) UV irradiation exposure.

literature for PP [20-23], as $840,1166,1455$ and $2720 \mathrm{~cm}^{-1}$. The peak at $1455 \mathrm{~cm}^{-1}$ is overlapped with several others [24], whereas 840 and $1166 \mathrm{~cm}^{-1}$ are sensitive to PP crystallinity [25]. Consequently, the peak at $2720 \mathrm{~cm}^{-1}$, associated with $\mathrm{CH}_{3}$ stretching and $\mathrm{CH}$ bending, was chosen as the most appropriate [20,26].

By comparing in Fig. 7, the area evolution of the carbonyl peak absorption band (in the range $\left[1700-1800 \mathrm{~cm}^{-1}\right]$ ) between the exposed samples and the unexposed unfilled PP, it is clearly visible that it increases after the UV irradiation treatment. From the FTIR

Table 4

TGA measurement results before and after three months of UV irradiation exposure.

\begin{tabular}{|c|c|c|c|c|}
\hline \multirow[t]{2}{*}{ Sample } & \multicolumn{2}{|c|}{$\begin{array}{l}\text { Before UV irradiation } \\
\text { exposure }\end{array}$} & \multicolumn{2}{|c|}{$\begin{array}{l}\text { After UV irradiation } \\
\text { exposure }\end{array}$} \\
\hline & $* \mathrm{~T}_{-5 \%}\left({ }^{\circ} \mathrm{C}\right)$ & ${ }^{*} T_{\max }\left({ }^{\circ} \mathrm{C}\right)$ & $\mathrm{T}_{-5 \%}\left({ }^{\circ} \mathrm{C}\right)$ & $T_{\max }\left({ }^{\circ} \mathrm{C}\right)$ \\
\hline$(\mathrm{UV}-) \mathrm{PP}$ & $431 \pm 1$ & $472 \pm 1$ & $281 \pm 1$ & $461 \pm 1$ \\
\hline (UV-)PP_Y ${ }_{2} \mathrm{O}_{3} \_0.1$ & $433 \pm 1$ & $474 \pm 1$ & $271 \pm 1$ & $457 \pm 1$ \\
\hline (UV-)PP_CeO $2 \_0.1$ & $434 \pm 1$ & $465 \pm 1$ & $364 \pm 1$ & $465 \pm 1$ \\
\hline (UV-)PP_Nd ${ }_{2} \mathrm{O}_{3}{ }_{2} 0.1$ & $435 \pm 1$ & $474 \pm 1$ & $277 \pm 1$ & $456 \pm 1$ \\
\hline (UV-)PP_Gd ${ }_{2} \mathrm{O}_{3}-0.1$ & $433 \pm 1$ & $475 \pm 1$ & $274 \pm 1$ & $453 \pm 1$ \\
\hline (UV-)PP_Dy ${ }_{2} \mathrm{O}_{3}{ }_{2} 0.1$ & $434 \pm 1$ & $472 \pm 1$ & $243 \pm 1$ & $449 \pm 1$ \\
\hline (UV-)PP_Er ${ }_{2} \mathrm{O}_{3} \_0.1$ & $435 \pm 1$ & $474 \pm 1$ & $267 \pm 1$ & $456 \pm 1$ \\
\hline (UV-)PP_Yb ${ }_{2} \mathrm{O}_{3}{ }_{-} 0.1$ & $436 \pm 1$ & $476 \pm 1$ & $285 \pm 1$ & $458 \pm 1$ \\
\hline$(\mathrm{UV}-) \mathrm{PP} \_\mathrm{Y}_{2} \mathrm{O}_{3} \_1$ & $434 \pm 1$ & $474 \pm 1$ & $288 \pm 1$ & $462 \pm 1$ \\
\hline (UV-)PP_CeO $2 \_1$ & $434 \pm 1$ & $473 \pm 1$ & $406 \pm 1$ & $469 \pm 1$ \\
\hline (UV-)PP_Nd ${ }_{2} \mathrm{O}_{3} \_1$ & $435 \pm 1$ & $474 \pm 1$ & $289 \pm 1$ & $460 \pm 1$ \\
\hline (UV-)PP_Gd ${ }_{2} \mathrm{O}_{3} \_1$ & $434 \pm 1$ & $476 \pm 1$ & $272 \pm 1$ & $458 \pm 1$ \\
\hline (UV-)PP_Dy ${ }_{2} \mathrm{O}_{3-1}$ & $435 \pm 1$ & $473 \pm 1$ & $261 \pm 1$ & $460 \pm 1$ \\
\hline (UV-)PP_Er ${ }_{2} \mathrm{O}_{3} \_1$ & $434 \pm 1$ & $476 \pm 1$ & $269 \pm 1$ & $454 \pm 1$ \\
\hline (UV-)PP_Yb $\mathrm{Yb}_{2} \mathrm{O}_{3} 1$ & $434 \pm 1$ & $475 \pm 1$ & $265 \pm 1$ & $454 \pm 1$ \\
\hline
\end{tabular}

$* \mathrm{~T}_{-5 \%}$ : Temperature at $5 \%$ weight loss, $T_{\max }$ : temperature of maximum decomposition rate. 


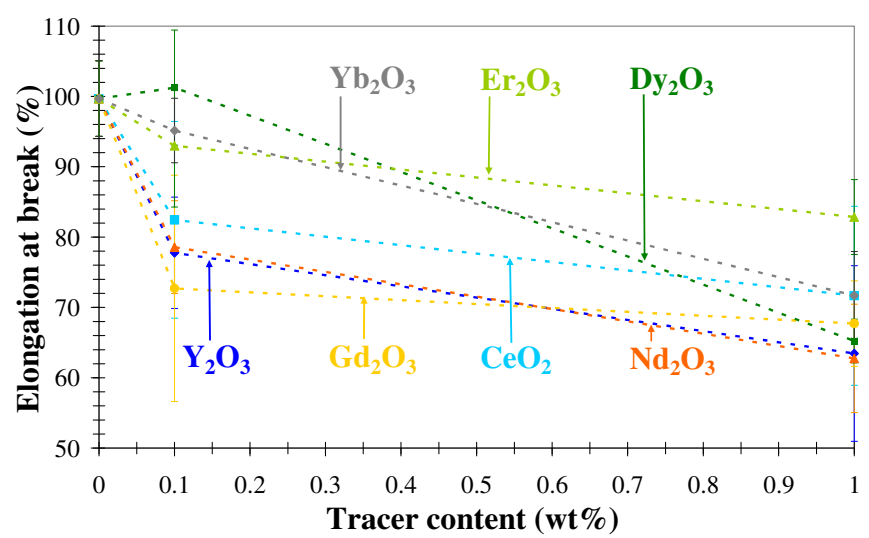

Fig. 11. Elongation at break as a function of tracer content before UV irradiation treatment.

spectrums, the lowest evolution after the UV exposition is observed for the UV-PP_CeO ${ }_{2} 1$ sample. For the remaining samples the evolution of the carbonyl peak is similar to the UV-PP submitted to weathering cycles.

The results obtained for the carbonyl index show that the carbonyl peak intensities decrease slightly with tracer content, except the $\mathrm{CeO}_{2}$ for which the carbonyl index decreases drastically compared to the UV-PP. Cerium oxide is well known to be an UV absorber [13], and these results show that it plays an important role in PP stabilization by delaying the photo-degradation process. The $\mathrm{CeO}_{2}$ particles act as optical filters by absorbing part of the UV irradiation and releasing the excess energy as heat, thus the UV intensity which can promote the oxidation of the PP chains is reduced. The same explication can be given for the $\mathrm{Y}_{2} \mathrm{O}_{3}$ particles which absorb the beginning of the UV irradiation at $300 \mathrm{~cm}^{-1}$ and this is the reason why its carbonyl index has a more important diminution compared to the other tracers.

By comparing the unfilled PP sample with the tracer filled PP samples after the UV irradiation treatment, no new peaks are observed, suggesting that their photo-degradation mechanisms are identical. Similar photo-stabilization effect of metal oxides has also been reported by Zhao et al., Tessier et al. and Sato et al. [12,13,26].

Regarding the remaining tracers $\left(\mathrm{Nd}_{2} \mathrm{O}_{3}, \mathrm{Gd}_{2} \mathrm{O}_{3}, \mathrm{Dy}_{2} \mathrm{O}_{3}, \mathrm{Er}_{2} \mathrm{O}_{3}\right.$ and $\mathrm{Yb}_{2} \mathrm{O}_{3}$ ) their effect on the photo-degradation of PP doesn't seem to play an important role.

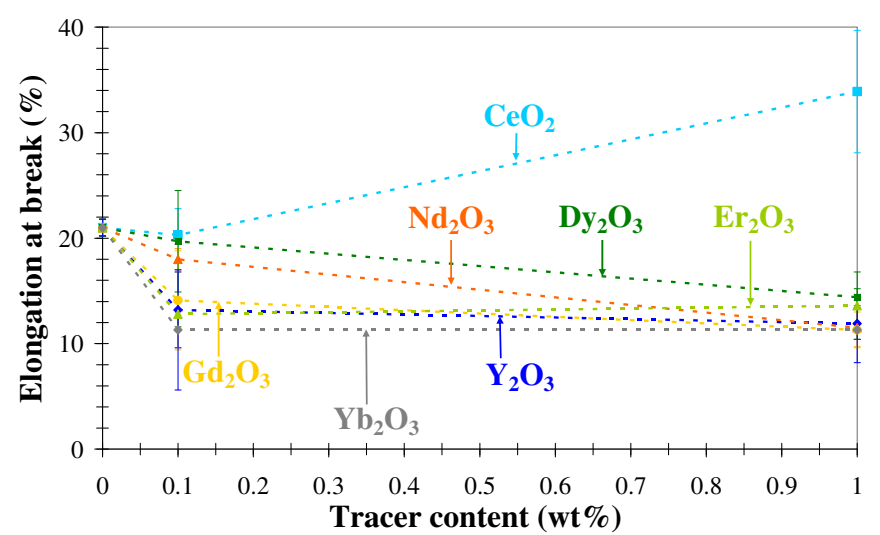

Fig. 13. Elongation at break as a function of tracer content after 10 days UV irradiation treatment.

\subsection{Effect of tracers on thermal and crystallization behaviours}

The thermal and crystallization data obtained from DSC for the unfilled PP and the traced polymer composites before UV irradiation exposure are summarized in Table 2 . As it can be reflected by $\Delta H_{f}, T_{m}, \Delta H_{c}$, and $T_{c}$ the melting and crystallization behaviours of the PP matrix are slightly affected by the tracer addition before UV irradiation treatment. Regarding the PP crystallinity $\left(\chi_{c}\right)$ the values are so close for considering a variation with the tracer addition. Even if it was expected that the rare earth oxides will act as nucleating agents [8-10] in polymer crystallization by increasing the crystallinity, their micrometric size seems to prevent them for having a real impact. In fact the average particle size of the rare earth oxides studied by Liu et al. $[8,9]$ was in the range [0.05- $0.6 \mu \mathrm{m}]$, in contrary to the particles used in this study that was superior to $1 \mu \mathrm{m}$.

By comparing the data in Tables 2 and 3 and the DSC thermograms displayed in Fig. 9, it can be seen that UV irradiation exposure has a real impact on both melting and crystallization behaviours of the PP matrix. The melting temperature of the unfilled PP dropped from 166.7 to $137.6{ }^{\circ} \mathrm{C}$ after 3 months of UV irradiation. This decrease of about $30^{\circ} \mathrm{C}$, is observed for almost all the traced samples, except the one containing $\mathrm{CeO}_{2}$ at $1 \mathrm{wt} \%$ (PP_CeO ${ }_{2}$ 1). The chain scission caused by photo-degradation can release the entanglement of molecules and produce more freed segments, thus the recrystallised material (Fig. 9) contains molecules that are smaller and defective due to groups like carbonyls.

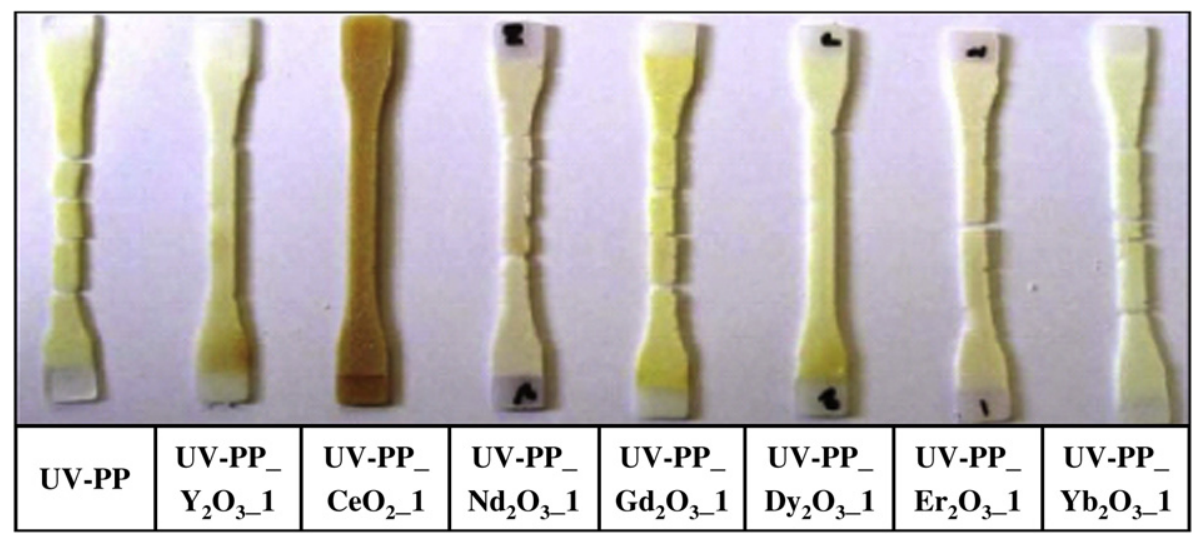

Fig. 12. Picture of specimens after 3 months UV irradiation treatment. 

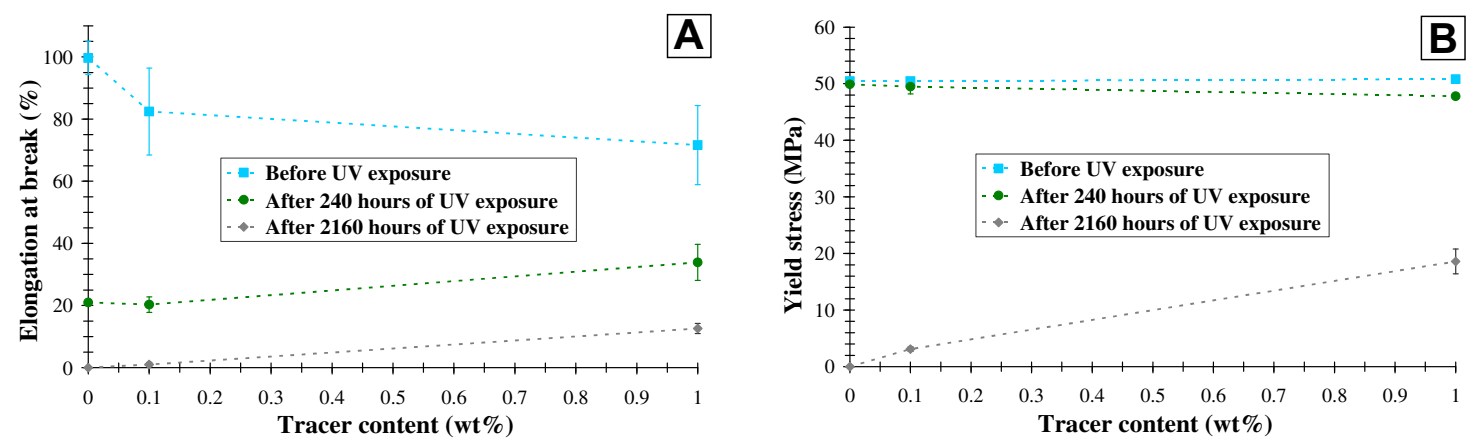

Fig. 14. Effect of UV irradiation exposure on the elongation at break (A) and yield stress (B) for the $\mathrm{CeO}_{2}$ traced $\mathrm{PP}$ samples.

Consequently, the reduction of molecular weight leads to the decrease of the melting temperature.

\subsection{Effect of tracers on thermal stability}

The addition of rare earth oxides in the PP matrix could improve the thermal stability and onset degradation [10]. The TGA measurement results before and after the UV irradiation treatment, are shown in Fig. 10 and Table 4. From the TGA curves of Fig. 10, it is obvious that the thermal decomposition for all the samples is a one-step process. PP thermally degrades to volatile products above $250{ }^{\circ} \mathrm{C}$ through a radical chain reaction process propagated by carbon centred radicals due to the lack of oxygen. The formed radicals initiate and propagate the subsequent radical chain reactions [26,27].

In Fig. 10-A, it can be seen that the TGA curves of the samples containing the tracers are nearly overlapping with the unfilled PP. By comparing the results before the UV irradiation exposure in Table 4, the temperatures of $5 \%$ weight loss $\left(\mathrm{T}_{-5} \%\right.$ ) and of maximum decomposition rate $\left(T_{\max }\right)$ for the traced materials appear to be superior to $1-5{ }^{\circ} \mathrm{C}$ than the unfilled PP. This means that rare earth oxides could provide thermal stability to the PP matrix, even though better results could be obtained by increasing their content [10].

Fig. 10-B shows that the majority of TGA curves of the UV irradiation exposed traced samples are close to the unfilled UV-PP, except the UV-PP_CeO $2 \_1$ sample for which the TGA curve is closer to the unexposed unfilled PP. Moreover, by comparing the results of $\mathrm{T}_{5}$ \% for the UV irradiation exposed samples with the unexposed unfilled PP sample, it appears that it drops dramatically of about $125{ }^{\circ} \mathrm{C}$. On the contrary, for the samples containing the $\mathrm{CeO}_{2}$ this diminution is of about $70{ }^{\circ} \mathrm{C}$ and $25^{\circ} \mathrm{C}$ for the 0.1 and $1 \mathrm{wt} \%$ tracer content, respectively. The positive thermal stability provided by cerium oxide can be explained by the protective effect upon UV irradiation due to the UV screening properties of $\mathrm{CeO}_{2}$ particles.

\subsection{Effect of tracers on mechanical properties}

In previous work [2], it has been shown that the addition of $1 \mathrm{wt}$ $\%$ of $\mathrm{Nd}_{2} \mathrm{O}_{3}$ and $\mathrm{Gd}_{2} \mathrm{O}_{3}$ leads to a slight increase of the Young's modulus and a slight decrease of the yield stress. Regarding the tensile tests, the most important effect of these rare earth oxides was observed on the elongation at break. Fig. 11 presents the results of elongation at break for all the tracers used in this study before UV irradiation exposure.

Predictably, the obtained results reveal that the elongation at break drops upon increasing the filler fraction [28-30]. However, at $0.1 \mathrm{wt} \%$ tracer content, the elongation at break slightly decreases from 5 to $25 \%$ with a standard deviation of about 5-15\%. The obtained values are close to the standard deviation of measurements and hence it can be considered that the influence of rare earth oxides in mechanical properties is minor at $0.1 \mathrm{wt} \%$.
As it can be seen in Fig. 12, the ductility of the tensile specimens was reduced considerably after UV irradiation treatment. Indeed, the majority of the samples, except UV-PP_CeO ${ }_{2} 0.1$ and UVPP_CeO ${ }_{2} 1$, were brittle and it was difficult to carry out the tensile tests. Fig. 13 presents the results of elongation at break obtained for the samples submitted to 10 days UV irradiation treatment. The tensile tests results of UV-PP_CeO 2 -0.1 and UV-PP_CeO ${ }_{2} \_1$ for 10 days and 3 months UV irradiation exposure are displayed in Fig. 14.

Fig. 13 shows that elongation at break decreases significantly from about $100 \%$ to $20 \%$ for the samples exposed to UV irradiation. However, for the majority of samples containing the rare earth oxides at 0.1 and $1 \mathrm{wt} \%$ the values of elongation at break are similar to the unfilled exposed PP. The unique exception of the traced samples are UV-PP_CeO2_0.1 and UV-PP_CeO2_1 for which elongation at break and yield stress (Fig. 14) increase with $\mathrm{CeO}_{2}$ particle content.

Based on the mechanical tests results, it can be summarized that $\mathrm{Y}_{2} \mathrm{O}_{3}, \mathrm{Nd}_{2} \mathrm{O}_{3}, \mathrm{Gd}_{2} \mathrm{O}_{3}, \mathrm{Dy}_{2} \mathrm{O}_{3}, \mathrm{Er}_{2} \mathrm{O}_{3}$ and $\mathrm{Yb}_{2} \mathrm{O}_{3}$ of micrometric mean particle size, have a minor effect on the photo-degradation of the PP matrix at $0.1 \mathrm{wt} \%$. On the contrary the addition of $1 \mathrm{wt} \%$ of $\mathrm{CeO}_{2}$ can act as an effective UV light screen for reducing the degree of photodegradation of the PP matrix.

\section{Conclusions}

Results from this work reveal that the addition of rare earth oxides of micrometric particle size at $0.1 \mathrm{wt} \%$ content in the PP matrix has a minor effect on the mechanical and thermal properties of the traced materials as well as on the photo-degradation of the polymer after UV irradiation exposure.

However, the addition of $1 \mathrm{wt} \%$ of rare earth oxides particles into the PP matrix decreases the elongation at break by $10-50 \%$ before UV irradiation treatment for a cross-head speed of $250 \mathrm{~mm} / \mathrm{min}$. For the same concentration, the melting and crystallization behaviours are slightly increased, whereas the thermal stability is improved, increasing the temperatures of $5 \%$ weight loss and maximum decomposition rate by $1-5^{\circ} \mathrm{C}$.

Regarding the UV irradiation treatment, the results of FTIR, DSC and ATG analysis together with mechanical characterization, pointed out that the addition of $\mathrm{CeO}_{2}$ particles in the PP matrix, which is believed to contain low quantities of UV stabilizers, can lead to significant improvements on the photo-degradation resistance of PP to UV exposure. Indeed, the $\mathrm{CeO}_{2}$ particles act as UV filters by absorbing part of the UV irradiation and thus reducing the UV intensity which can promote the oxidation of the PP chains. For the remaining tracers, the results obtained show the same behaviour on the photo-degradation as in the case of the unfilled PP matrix.

The dispersion effect of tracers in the PP matrix was quantitatively characterized by applying image processing to the SEM images with the help of MATLAB. The distance to the first ten neighbouring spheres calculated for the SEM data was compared 
with the theoretical distance for a cubic and a hexagonal close packing arrangement of the same surface and the same number of particles as in the case of the experimental data. The SEM images and the results obtained from image processing show a homogenous dispersion of tracers in the PP matrix.

In order to study the effect of rare earth oxides in the PP matrix a polypropylene homopolymer free of fillers like talc and calcium carbonate and which is believed to contain only low quantities of UV stabilizers was chosen in this study. As it was shown, $\mathrm{CeO}_{2}$ particles can act as UV absorbers by protecting the polymer matrix from photo-degradation. Complementary work can be carried out with other grades of PP, more adapted to outdoor environment applications, for studying probable antagonistic effects between the $\mathrm{CeO}_{2}$ particles and the UV stabilizers already contained in the polymer matrix.

\section{Acknowledgements}

The authors would like to thank the French Industry-University Cooperative Research Network on Waste (RECORD - www.recordnet.org), the French Environment and Energy Management Agency (ADEME - www.ademe.fr) for their contribution to the funding of this work and for providing industrial orientations and scientific supervision to the research.

\section{References}

[1] Bezati F, Froelich D, Massardier V, Maris E. Waste Manage 2010;30:591-6.

[2] Bezati F, Massardier V, Froelich D, Maris E, Balcaen J. Waste Biomass Valor 2010;1:357-65.
[3] Ahmad SR. Environ Technol 2004;25:1143-9.

4] Linder C, Herold M. Plastic waste in European key countries. Plastics Europe; 2005.

[5] Sastry RLN, Yoganarasimhan SR, Mehrotra PN, Rao CNR. J Inorg and Nucl Chem 1966;28:1165-77.

[6] Lauwerys RR, Haufroid V, Huet P, Lison D. Toxicologie industrielle et intoxications professionnelles. Issy-les-Moulineaux: Elsevier Masson; 2007.

[7] Morteani G. Eur J Mineral 1991;3:641-50.

8] Liu J, Tang G, Qu G, Zhou H, Guo Q. J Appl Polym Sci 1993;47:2111-6.

[9] Ye C, Liu J, Mo Z, Tang G, Jing XJ. Appl Polym Sci 1996;60:1877-81.

[10] Xiaomin Z, Jingshu L, Zhihui Y, Jinghua Y. J Appl Polym Sci 1996;62:313-8.

[11] Fauchadour D, Jeanson T, Bousseau JN, Echalier B. Application to coatings technologies. 2005.

[12] Sato T, Katakuraa T, Yina S, Fujimotob T, Yabec S. Solid State Ionics 2004;172: $377-82$.

[13] Tessier F, Cheviré F, Muñoz F, Merdrignac-Conanec O, Marchand R, Bouchard M, et al. J Solid State Chem 2008;181:1204-12.

[14] Bezuidenhout DF, Pretorius R. Thin Solid Films 1986;139:121-32.

[15] Atanassov G, Thielsch R, Popov D. Thin Solid Films 1993;223:288-92.

[16] http://www.labomat.com/Produits/QUV.php.

[17] Brandrup J, Immergut EH. Polymer Handbook. 3rd ed. New York: Wiley; 1989.

[18] Gendron R, Binet D. J Vinyl Addit Techn 1998;4:54-9.

[19] Liang JZ. Composites 2007;38:1502-6.

[20] Rabello M, White JR. Polym Degrad Stabil 1995;56:55-73.

[21] Blinov NN, Popov AA, Rakovski SK, Stoyanov AK, Shopov DM, Zaikov GY. Polymer Science U.S.S.R 1989;31:2434-9.

[22] Livanova NM, Zaikov GE. Polym Degrad Stabil 1992;36:253-9.

[23] Katbab AA, Moushirabadi AY. Radiat Phys Chem 1991;38:295-301.

[24] Morales E, White JR. J Mater Sci 1988;23:3612-22.

[25] Karcan I, Taraiya AK, Bower DI, Wardi M. Polymer 1993;34:2691-701.

[26] Zhao H, Li RKY. Polymer 2006;47:3207-17.

[27] Zanetti M, Camino G, Reichert P, Mulhaupt R. Macromol Rapid Comm 2001;22:176-80.

[28] Thio YS, Argon AS, Cohen RE, Weinberg M. Polymer 2002;43:3661-74.

[29] Zuiderduin WCJ, Westzaan C, Huétink J, Gaymans RJ. Polymer 2003;44: 261-75.

[30] Leong YW, Ishak ZAM, Ariffin A. J Appl Polym Sci 2004;91:3327-36. 